\title{
Patologia Dermatológica em Doentes Transplantados Hepáticos e Renais Referenciados à Consulta de Dermatologia e Venereologia
}

\author{
Skin Disease in Liver and Kidney Transplant Recipients Referred to the \\ Department of Dermatology and Venereology
}

\author{
Sónia FERNANDES ${ }^{1}$, Ana Sofia CARRELHA², Gabriela MARQUES PINTO ${ }^{1}$, Fernando NOLASCO ${ }^{3}$, Eduardo \\ BARROSO ${ }^{2}$, Jorge CARDOSO ${ }^{1}$
}

Acta Med Port 2013 Sep-Oct;26(5):555-563

\section{RESUMO}

Introdução: Foram descritas várias doenças cutâneas em doentes transplantados, em relação com a terapêutica imunossupressora instituída. Pretendemos caracterizar o espectro clínico das patologias dermatológicas e comparar os diagnósticos entre os doentes transplantados hepáticos e os doentes transplantados renais.

Material e Métodos: Estudo descritivo e retrospectivo através da consulta de processos clínicos de todos os doentes submetidos a transplante hepático ou renal entre 2000 - 2010 referenciados à Consulta de Dermatologia e Venereologia.

Resultados: Observámos 319 doentes transplantados (23,5\%) e apurámos 410 diagnósticos (230 na sub-população com transplante hepático e 180 na sub-população com transplante renal), divididos em quatro grupos: 1) infecções cutâneas; 2) cancro cutâneo ou lesões precursoras; 3) manifestações cutâneas relacionadas com efeitos secundários de fármacos; 4) outras patologias dermatológicas não iatrogénicas. As infecções cutâneas foram as mais observadas (42,2\%), em média 32,7 meses após o transplante. Este grupo incluiu $20,5 \%$ de infecções fúngicas, $12,7 \%$ virais e $8,5 \%$ bacterianas. Identificámos patologia tumoral e lesões precursoras em $11,7 \%$ dos casos, em média 44,8 meses após o transplante e assumindo maior importância na sub-população com transplante renal (20,6\% vs $4,8 \%$ nos transplantados hepáticos; $P<0,001)$. Os transplantados renais apresentaram predomínio de carcinomas espinocelulares (CEC) sobre os casos de carcinomas basocelulares (CBC), numa razão CEC:CBC de 1,3:1 mas nos transplantados hepáticos verificou-se uma razão $C B C$ : carcinomas de 3,5:1. Ocorreram efeitos secundários de fármacos em 10,5\% dos casos e outras patologias dermatológicas não iatrogénicas em $35,6 \%$.

Discussão: Apesar da patologia tumoral ser a mais referida na literatura, as infecções cutâneas foram as mais observadas na nossa amostra. As diferenças significativas entre as duas sub-populações estudadas podem estar relacionadas com o maior grau de imunossupressão a que os doentes transplantados renais estão sujeitos.

Conclusão: Dada a elevada frequência de patologia cutânea nestes doentes é essencial incluir o acesso a consultas de Dermatologia e Venereologia nos cuidados multi-disciplinares pós-transplante.

Palavras-chave: Transplante de Fígado; Transplante de Rim; Imunossupressão/efeitos adversos; Doenças da Pele; Infecções Cutâneas; Neoplasias da Pele; Carcinoma Basocelular; Carcinoma Espinocelular.

\section{ABSTRACT}

Introduction: Several skin disorders, immunosuppression-induced, have been described in transplant recipients. The aim of our study is to characterize the clinical spectrum of skin disorders and to compare the findings in liver and kidney transplant recipients.

Material and Methods: A retrospective descriptive study was conducted. Data were collected from the medical records of all liver and kidney transplant recipients from 2000 - 2010 who had been referred to our Dermato-Venereology Department.

Results: Three hundred nineteen transplant recipients (23.5\%) have been seen, resulting in 410 diagnoses (230 in the subpopulation of liver transplant recipients and 180 in the subpopulation of kidney transplant recipients) grouped into 4 categories: 1) cutaneous infections; 2) skin cancer or premalignant skin lesions; 3) cutaneous side-effects; 4) non-iatrogenic skin disorders. Cutaneous infections were the most common presentations (42.2\%), on average 32.7 months after transplantation. The latter group included $20.5 \%$ of fungal, $12.7 \%$ viral and $8.5 \%$ bacterial infections. Skin cancer and premalignant skin lesions made up $11.7 \%$ of all diagnoses, over a mean of 44.8 months post transplant and occurring primarily in kidney transplant recipients $(20.6 \% \mathrm{vs} 4.8 \%$ in liver transplantation patients; $P<0.001)$. The kidney transplant population had a squamous cell carcinoma (SCC) to basal cell carcinoma (BCC) ratio of $1.3: 1$ with SCC predominance, and the liver transplant population had a BCC:SCC ratio of 3.5:1. We also identified $10.5 \%$ of cutaneous sideeffects and $35.6 \%$ of non-iatrogenic skin disorders.

Discussion: Although neoplastic pathology is more frequently mentioned in the literature, cutaneous infections were the most common diagnoses in our study. The significant differences between the two subpopulations studied may be related to higher immunosuppression after kidney transplantation.

Conclusion: The high number of skin disorders reported in these patients makes it essential for Dermato-Venereology to be included within the multidisciplinary post-transplant care provided.

Keywords: Liver Transplantation; Kidney Transplantation; Immunosuppression/adverse effects; Skin diseases; Skin diseases, infectious; Skin Neoplasms; Carcinoma, Basal Cell; Carcinoma, Squamous Cell.

\footnotetext{
1. Serviço de Dermatologia e Venereologia. Hospital Curry Cabral. Lisboa. Portugal.

2. Centro Hepato-Bílio-Pancreático e Transplantação. Hospital Curry Cabral. Lisboa. Portugal.

3. Unidade de Transplantação e Serviço de Nefrologia. Hospital Curry Cabral. Lisboa. Portugal.

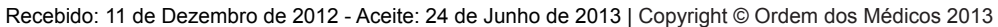




\section{INTRODUÇÃO}

Foram descritas várias doenças cutâneas em doentes transplantados, em relação com a terapêutica imunossupressora instituída, nomeadamente patologia infecciosa, tumoral e efeitos secundários dos fármacos utilizados. ${ }^{1-10}$ Face ao crescente número de doentes transplantados e à reconhecida melhoria na qualidade dos cuidados prestados a estes doentes no nosso país, importa perceber quais os principais diagnósticos do foro dermatológico que motivam a solicitação de consulta, de modo a melhor adequar as respostas dadas.

O presente trabalho visa caracterizar o espectro das doenças cutâneas observadas em doentes com transplante de órgão sólido (hepático ou renal) seguidos num centro de referência em Transplantação de um Hospital terciário e referenciados à Consulta de Dermatologia e Venereologia, comparando os diagnósticos da sub-população com transplante hepático com os da sub-população com transplante renal.

\section{MATERIAL E MÉTODOS}

Foi realizado um estudo descritivo e retrospectivo de variáveis demográficas e clínicas de doentes submetidos a transplante hepático ou renal pela Unidade de Transplantação do Hospital Curry Cabral (Lisboa, Portugal) entre 1 de Janeiro de 2000 e 31 de Dezembro de 2010. Os dados foram obtidos através da revisão dos processos clínicos de todos os doentes com idade superior a 18 anos e com seguimento mínimo de um mês após o transplante, referenciados à Consulta de Dermatologia e Venereologia no Hospital Curry Cabral até Dezembro de 2011. O acesso à referida consulta é feito por referenciação médica, podendo o pedido ser efectuado com carácter de urgência e observação do doente no dia imediato, ou ser solicitada observação por marcação após triagem. Foram excluídos todos os doentes submetidos a duplo transplante (hepático e renal) e 13 doentes por ausência de registos clínicos adequados. A análise estatística foi realizada utilizando o software SPSS versão 17.0 (SPSS Inc; Chicago, Illinois, United States of America).

\section{RESULTADOS}

Os autores dividiram os diagnósticos do foro dermatológico em quatro grupos: 1) infecções cutâneas; 2) cancro cutâneo ou lesões precursoras; 3) manifestações cutâneas relacionadas com efeitos secundários de fármacos; 4) outras patologias dermatológicas não iatrogénicas. Ambas as sub-populações (doentes transplantados hepáticos e doentes transplantados renais) estavam sob esquemas de terapêutica imunossupressora similares com associações de fármacos que podem dividir-se grosseiramente em quatro classes: A) corticosteróides - prednisolona; B) inibidores da calcineurina - tacrolimus ou ciclosporina; C) agentes anti-proliferativos - micofenolato de mofetil ou azatioprina e D) inibidores da proteína cinase mTOR - sirolimus ou everolimus, com esquemas terapêuticos que visam conferir maior grau de imunossupressão nos doentes transplantados renais. A descrição da amostra é apresentada na Tabela 1.

\section{Grupo 1 - Infecções cutâneas}

Observámos 173 casos (42,2\%; 173/410) de infecções cutâneas (grupo 1), em indivíduos com uma idade média de 49,4 anos ( $s=12,5$; variação, $22-74$ anos), $68,8 \%$ do sexo masculino. Nas sub-populações estudadas identificámos 93 casos $(40,4 \%$; 93/230) nos doentes com transplante hepático e 80 (44,4\%; 80/180) nos doentes com transplante renal. Na sub-população de transplantados hepáticos a idade média observada foi de 48,9 anos ( $s=12,7$; variação 23 - 74 anos) e o intervalo médio desde a data do transplante foi de 33,4 meses ( $s=29,1$; variação, 1-120 meses). Na sub-população de transplantados renais a idade média observada foi de 50,0 anos ( $s=12,1$; variação $22-68$ anos) e o intervalo médio desde a data do transplante foi de 32,1 meses ( $s=30,2$; variação, 1-120 meses).

Os diagnósticos do grupo 1 são apresentados em detaIhe na Tabela 2.

As infecções fúngicas foram o principal motivo de consulta identificado $(20,5 \%)$. Nestes 84 casos estabelecemos o diagnóstico de dermatofitia em 52 (61,9\%), pitiriase versicolor em $24(28,6 \%)$ e candidíase em $8(9,5 \%)$. Nos casos de dermatofitia o resultado do exame micológico directo e cultural encontrava-se disponível em 22 doentes (dos quais seis corresponderam a infecções por Trichophyton $(T$.) rubrum, quatro casos de T. mentagrophytes var. interdigitale, quatro casos de $T$. soudanense, três casos de Microsporum (M.) canis, três casos de T. mentagrophytes var. mentagrophytes e dois casos de $M$. audouinii), não tendo sido encontrados casos de micose profunda no período do estudo. Dos 35 casos com infecções bacterianas, 16 corresponderam a foliculite $(45,7 \% ; 16 / 35)$, seis a abcessos por Staphylococcus aureus $(17,1 \% ; 6 / 35)$, celulite/erisipela em cinco $(14,3 \% ; 5 / 35)$, impétigo em quatro $(11,4 \% ; 4 / 35)$ e os restantes quatro diagnósticos corresponderam a casos iso-

Tabela 1 - Descrição da amostra.

\begin{tabular}{lccr}
\hline & Total & Transplante Hepático & Transplante Renal \\
\hline Transplantes & 1408 & 908 & 500 \\
Transplantados & 1357 & 871 & 486 \\
Consulta de Dermatologia e Venereologia & 319 & 179 & 140 \\
Diagnósticos apurados & $\mathbf{4 1 0}$ & 230 & 180 \\
\hline
\end{tabular}


lados de infecção por Borrelia, Treponema pallidum, Neisseria gonorrhoeae e Chlamydia trachomatis. As infecções virais foram diagnosticadas em 12,7\% das consultas: 32 casos de infecção pelo vírus do papiloma humano (HPV) dos quais 28 verrugas vulgares $(87,5 \%$; $28 / 32)$ e quatro condilomas ano-genitais (12,5\%; 4/32); 20 casos de infecção pelo vírus herpes (HHV) dos quais 15 herpes zoster (75\%; 15/20) por reactivação da infecção do vírus varicela zoster (HHV-3) e cinco casos $(25 \%$; 5/20) de infecção por herpes simplex (HSV1/HSV2).

As diferenças encontradas nas duas sub-populações não foram estatisticamente relevantes.

\section{Grupo 2 - Cancro cutâneo ou lesões precursoras}

Em 48 casos $(11,7 \%$; 48/410) foi estabelecido o diagnóstico de lesões precursoras ou cancro cutâneo, em indivíduos com idade média de 61,4 anos ( $s=8,5$; variação, 35-78 anos), 85,4\% do sexo masculino. Nas sub-populações estudadas identificámos 11 casos (4,8\%; 11/230) nos doentes com transplante hepático e 37 (20,6\%; 37/180) nos doentes com transplante renal.

Na sub-população de transplantados hepáticos a idade média observada foi de 61,8 anos ( $s=7,0$; variação $45-70$ anos) e o intervalo médio desde a data do transplante foi de 32,7 meses ( $s=33,6$; variação $12-132$ meses). Na sub-população de transplantados renais a idade média observada foi de 60,7 anos ( $s=8,9$; variação $35-78$ anos) e o intervalo médio desde a data do transplante foi de 48,4 meses ( $s=$ 33,1; variação 4-120 meses).

Os diagnósticos do grupo 2 são apresentados em detaIhe na Tabela 3.

No grupo 2, os 33 casos de cancro cutâneo não melanoma confirmados histologicamente representam 15 $(45,5 \% ; 15 / 33)$ diagnósticos de carcinoma basocelular (sete em transplantados hepáticos e oito em transplantados renais), 14 (42,4\%; 14/33) diagnósticos de carcinoma espinocelular (dois em transplantados hepáticos e 12 em transplantados renais) e quatro indivíduos (12,1\%; 4/33),

Tabela 2 - Diagnósticos do GRUPO 1 - Infecções cutâneas.

\begin{tabular}{|c|c|c|c|c|c|c|}
\hline \multicolumn{2}{|c|}{ Diagnóstico } & $\begin{array}{l}\text { Número de } \\
\text { casos } \\
(n=410)\end{array}$ & $\begin{array}{c}\text { Tempo médio até } \\
\text { diagnóstico } \\
\text { (meses) }\end{array}$ & $\begin{array}{c}\text { Transplante } \\
\text { Hepático - casos } \\
\text { diagnosticados } \\
(n=230)\end{array}$ & $\begin{array}{c}\text { Transplante } \\
\text { Renal - casos } \\
\text { diagnosticados } \\
(n=180)\end{array}$ & $\begin{array}{c}\text { Nível de } \\
\text { significância* }\end{array}$ \\
\hline \multicolumn{2}{|c|}{ Infecções fúngicas } & $84(20,5 \%)$ & $28,7(1-120)$ & $49(21,3 \%)$ & $35(19,4 \%)$ & $p=0,156$ \\
\hline \multicolumn{2}{|c|}{ Infecções bacterianas } & $35(8,5 \%)$ & $35,6(3-120)$ & $23(10,0 \%)$ & $12(6,7 \%)$ & $p=0,090$ \\
\hline \multirow{2}{*}{$\begin{array}{l}\text { Infecções } \\
\text { Virais }\end{array}$} & Infecção HPV & $32(7,8 \%)$ & $43,2(1-120)$ & $14(6,1 \%)$ & $18(10,0 \%)$ & $p=0,597$ \\
\hline & Infecção HHV & $20(4,9 \%)$ & $29,1(7-84)$ & $7(3,0 \%)$ & $13(7,2 \%)$ & $p=0,263$ \\
\hline \multicolumn{2}{|c|}{$\begin{array}{l}\text { Infecção parasitária } \\
\text { (Escabiose) }\end{array}$} & $2(0,5 \%)$ & $18,0(12-24)$ & 0 & $2(1,1 \%)$ & - \\
\hline \multicolumn{2}{|l|}{ TOTAL } & $173(42,2 \%)$ & $32,7(1-120)$ & $93(40,4 \%)$ & $80(44,4 \%)$ & $p=0,362$ \\
\hline
\end{tabular}

HPV - vírus do papiloma humano; HHV - vírus herpes;

* Foram realizados teste binominais para avaliar se existiam diferenças estatisticamente significativas entre ambas as sub-populações (doentes com transplante hepático e doentes com transplante renal) com nivel de significância de $5 \%(p<0,05)$.

Tabela 3 - Diagnósticos do GRUPO 2 - Cancro cutâneo ou lesões precursoras.

\begin{tabular}{|c|c|c|c|c|c|}
\hline Diagnóstico & $\begin{array}{l}\text { Número de } \\
\text { casos } \\
(n=410)\end{array}$ & $\begin{array}{l}\text { Tempo médio } \\
\text { até diagnóstico } \\
\text { (meses) }\end{array}$ & $\begin{array}{l}\text { Transplante Hepático - } \\
\text { casos diagnosticados } \\
\qquad(n=230)\end{array}$ & $\begin{array}{l}\text { Transplante Renal - } \\
\text { casos diagnosticados } \\
\quad(n=180)\end{array}$ & $\begin{array}{c}\text { Nível de } \\
\text { significância* }\end{array}$ \\
\hline Queratose actínica & $10(2,4 \%)$ & $40,8(12-108)$ & $1(0,4 \%)$ & $9(5 \%)$ & $p=0,021$ \\
\hline Queilite actínica & $2(0,5 \%)$ & $24(20-28)$ & 0 & $2(1,1 \%)$ & - \\
\hline $\begin{array}{l}\text { Cancro cutâneo não- } \\
\text { melanoma [CBC e CEC] }\end{array}$ & $33(8,0 \%)$ & $49,9(4-132)$ & $9(3,9 \%)$ & $24(13,3 \%)$ & $p=0,014$ \\
\hline Sarcoma de Kaposi & $2(0,5 \%)$ & $14,5(5-24)$ & $1(0,4 \%)$ & $1(0,6 \%)$ & $p=1,000$ \\
\hline Melanoma maligno & $1(0,2 \%)$ & 19 & 0 & $1(0,6 \%)$ & - \\
\hline TOTAL & $48(11,7 \%)$ & $44,8(4-132)$ & $11(4,8 \%)$ & $37(20,6 \%)$ & $p<0,001$ \\
\hline
\end{tabular}

CBC - carcinoma basocelular; CEC - carcinoma espinocelular;
* Foram realizados teste binominais para avaliar se existiam diferenças estatisticamente significativas entre ambas as sub-populações (doentes com transplante hepático e doentes com transplante renal) com nível de significância de $5 \%(p<0,05)$ 
todos transplantados renais, com diagnóstico concomitante de carcinoma basocelular e de carcinoma espinocelular. Estes diagnósticos assumiram maior importância na sub-população de doentes com transplante renal, tendo sido o motivo de consulta em $13,3 \%$ dos casos mas apenas em $3,9 \%$ dos transplantados hepáticos, e esta diferença foi estatisticamente significativa $(p=0,014)$. O tempo médio até ao diagnóstico de cancro cutâneo não melanoma nos 24 doentes com transplante renal foi de 55,2 meses e nos nove doentes com transplante hepático foi de 36 meses (Tabela 4). No global, os diagnósticos do grupo 2 foram mais observados nos transplantados renais (foram motivo de consulta em $20,6 \%$ dos casos mas apenas em $4,8 \%$ dos doentes com transplante hepático) e esta diferença também foi estatisticamente significativa $(p<0,001)$.

\section{Grupo 3 - Manifestações cutâneas relacionadas com efeitos secundários de fármacos}

As manifestações cutâneas relacionadas com efeitos secundários de fármacos (grupo 3 ) foram motivo de consulta de Dermatologia em 43 casos (10,5\%; 43/410), em indivíduos com idade média de 46,8 anos ( $s=14,3$; variação, $18-70$ anos), 55,8\% do sexo masculino. Considerando as sub-populações estudadas identificámos 28 casos
$(12,2 \% ; 28 / 230)$ nos doentes com transplante hepático e $15(8,3 \% ; 15 / 180)$ nos doentes com transplante renal. $\mathrm{Na}$ sub-população de transplantados hepáticos a idade média observada foi de 46,9 anos ( $s=13,1$; variação 18-67 anos) e o intervalo médio desde a data do transplante foi de 31,9 meses ( $s=32,1$; variação, 2-108 meses). Na sub-população de transplantados renais a idade média observada foi de 46,7 anos ( $s=16,3$; variação $24-70$ anos) e o intervalo médio desde a data do transplante foi de 34,9 meses ( $s=$ 33,1; variação, 2-108 meses).

Os diagnósticos do grupo 3 são apresentados em detaIhe na Tabela 5, sem diferenças estatisticamente significativas no que concerne a distribuição entre as sub-populações.

\section{Grupo 4 - Outras patologias dermatológicas não iatro- génicas}

Foram observadas outras patologias dermatológicas não iatrogénicas em 146 casos (35,6\%; 146/410), em indivíduos com idade média de 50,4 anos ( $s=12,2$; variação, 26 - 76 anos) à data do diagnóstico e $63,7 \%$ do sexo masculino. Nas sub-populações estudadas identificámos 98 casos $(42,6 \% ; 98 / 230)$ nos doentes com transplante hepático e $48(26,7 \% ; 48 / 180)$ nos doentes com transplante renal.

Tabela 4 - Caracterização dos casos com diagnóstico de cancro cutâneo não-melanoma.

\begin{tabular}{|c|c|c|c|c|c|c|}
\hline & $\begin{array}{l}\text { Casos com } \\
\text { diagnóstico } \\
\text { de Carcinoma } \\
\text { Basocelular }\end{array}$ & $\begin{array}{c}\text { Casos com } \\
\text { diagnóstico } \\
\text { de Carcinoma } \\
\text { Espinocelular }\end{array}$ & $\begin{array}{c}\text { Casos com } \\
\text { diagnóstico } \\
\text { concomitante } \\
\text { de Carcinoma } \\
\text { Basocelular } \\
\text { e Carcinoma } \\
\text { Espinocelular }\end{array}$ & $\begin{array}{l}\text { Tempo médio } \\
\text { até diagnóstico } \\
\text { (meses) }\end{array}$ & $\begin{array}{l}\text { Idade média } \\
\text { (anos) }\end{array}$ & $\begin{array}{c}\text { Sexo masculino } \\
\text { (percentagem) }\end{array}$ \\
\hline $\begin{array}{l}\text { Transplante Hepático } \\
\qquad(n=9)\end{array}$ & 7 & 2 & 0 & $36(12-132)$ & 63,5 & $88,9 \%$ \\
\hline $\begin{array}{l}\text { Transplante Renal } \\
\qquad(n=24)\end{array}$ & 8 & 12 & 4 & $55,2(4-120)$ & 60,5 & $83,3 \%$ \\
\hline
\end{tabular}

Tabela 5 - Diagnósticos do GRUPO 3 - Manifestações cutâneas relacionadas com efeitos secundários de fármacos.

\begin{tabular}{|c|c|c|c|c|c|}
\hline Diagnóstico & $\begin{array}{l}\text { Número de } \\
\text { casos } \\
(n=410)\end{array}$ & $\begin{array}{l}\text { Tempo médio } \\
\text { até diagnóstico } \\
\text { (meses) }\end{array}$ & $\begin{array}{l}\text { Transplante Hepático - } \\
\text { casos diagnosticados } \\
(n=230)\end{array}$ & $\begin{array}{l}\text { Transplante Renal - } \\
\text { casos diagnosticados } \\
(n=180)\end{array}$ & $\begin{array}{c}\text { Nível de } \\
\text { significância* }\end{array}$ \\
\hline Erupção acneiforme & $14(3,4 \%)$ & $11,2(2-24)$ & $8(3,5 \%)$ & $6(3,3 \%)$ & $p=0,791$ \\
\hline Toxidermia & $13(3,2 \%)$ & $47,7(4-108)$ & $9(3,9 \%)$ & $4(2,2 \%)$ & $p=0,267$ \\
\hline Púrpura & $6(1,5 \%)$ & $44,0(12-108)$ & $3(1,3 \%)$ & $3(1,7 \%)$ & $p=1,000$ \\
\hline Hipertricose & $6(1,5 \%)$ & $27,0(2-72)$ & $5(2,2 \%)$ & $1(0,6 \%)$ & $p=0,219$ \\
\hline Estrias & $2(0,5 \%)$ & $44,5(5-84)$ & $1(0,4 \%)$ & $1(0,6 \%)$ & $p=1,000$ \\
\hline Hiperplasia gengival & $1(0,2 \%)$ & 72 & $1(0,4 \%)$ & 0 & - \\
\hline Úlceras orais & $1(0,2 \%)$ & 12 & $1(0,4 \%)$ & 0 & - \\
\hline TOTAL & $43(10,5 \%)$ & $32(2-108)$ & $28(12,2 \%)$ & $15(8,3 \%)$ & $p=0,066$ \\
\hline
\end{tabular}
com transplante renal) com nível de significância de $5 \%(p<0,05)$ 
Tabela 6 - Diagnósticos do GRUPO 4 - Outras patologias dermatológicas não iatrogénicas.

\begin{tabular}{|c|c|c|c|c|c|}
\hline Diagnóstico & $\begin{array}{c}\text { Número de } \\
\text { casos } \\
(n=410)\end{array}$ & $\begin{array}{l}\text { Tempo médio } \\
\text { até diagnóstico } \\
\text { (meses) }\end{array}$ & $\begin{array}{l}\text { Transplante Hepático - } \\
\text { casos diagnosticados } \\
(n=230)\end{array}$ & $\begin{array}{l}\text { Transplante Renal - } \\
\text { casos diagnosticados } \\
(n=180)\end{array}$ & $\begin{array}{c}\text { Nível de } \\
\text { significância* }\end{array}$ \\
\hline Eczema & $39(9,5 \%)$ & $46,9(1-120)$ & $28(12,2 \%)$ & $11(6,1 \%)$ & $p=0,009$ \\
\hline $\begin{array}{l}\text { Nevos melanocíticos } \\
\text { / Tumores cutâneos } \\
\text { benignos }\end{array}$ & $34(8,3 \%)$ & $38,8(1-132)$ & $27(11,7 \%)$ & $7(3,9 \%)$ & $p=0,001$ \\
\hline Dermite seborreica & $27(6,6 \%)$ & $31,4(8-96)$ & $19(8,3 \%)$ & $8(4,4 \%)$ & $p=0,052$ \\
\hline Xerose/Prurido & $13(3,2 \%)$ & $27,7(12-72)$ & $7(3,0 \%)$ & $6(3,3 \%)$ & $p=1,000$ \\
\hline Outras dermatoses & $33(8,0 \%)$ & $46,7(1-120)$ & $17(7,4 \%)$ & $16(8,9 \%)$ & $p=1,000$ \\
\hline TOTAL & $146(35,6 \%)$ & $39,7(1-132)$ & $98(42,6 \%)$ & $48(26,7 \%)$ & $p<0,001$ \\
\hline
\end{tabular}
com transplante renal) com nível de significância de $5 \%(p<0,05)$

Na sub-população de transplantados hepáticos a idade média observada foi de 49,9 anos ( $s=12,5$; variação 27 76 anos) e o intervalo médio desde a data do transplante foi de 39,9 meses ( $s=33,6$; variação, 1-132 meses). $\mathrm{Na}$ sub-população de transplantados renais a idade média observada foi de 51,5 anos ( $s=11,4$; variação $26-71$ anos) e o intervalo médio desde a data do transplante foi de 38,7 meses ( $s=26,2$; variação, 1-96 meses).

Os diagnósticos do grupo 4 são apresentados em detalhe na Tabela 6 , predominantemente observados em doentes com transplante hepático, e cuja distribuição entre as sub-populações apresentou diferenças estatisticamente significativas $(p<0,001)$.

\section{DISCUSSÃO}

Neste estudo foram avaliados os diagnósticos do foro dermatológico observados em doentes submetidos a transplante hepático ou renal no Hospital Curry Cabral entre 2000 e 2010 e referenciados à Consulta de Dermatologia e Venereologia até Dezembro de 2011. A análise dos dados revelou que cerca de um quarto dos doentes transplantados durante o período do estudo $(23,5 \%)$ foi observado por doenças cutâneas. Relativamente às patologias observadas, apesar de grande parte dos estudos anteriores sobre as manifestações cutâneas em doentes transplantados avaliar a patologia neoplásica, também foi identificada no nosso grupo de doentes uma pletora de outras patologias do foro dermatológico. ${ }^{1-10}$

$\mathrm{Na}$ pesquisa da literatura efectuada pelos autores não foram encontrados outros estudos com desenho ou objectivos semelhantes e que tivessem como população alvo os doentes transplantados renais e os doentes transplantados hepáticos. Contudo existem alguns trabalhos sobre patologia dermatológica em transplantados, quer a nível nacional, quer realizados por outros centros europeus. Referimos a título de exemplo um estudo realizado na Holanda por Wisgerhof et al ${ }^{11}$ que avaliou 801 doentes submetidos a transplante renal ou renal e pancreático, em que foi eviden- ciado um predomínio de infecções cutâneas (24\%), seguidas por tumores cutâneos benignos $(23,3 \%)$ e neoplasias cutâneas (18,2\%). Perera et al ${ }^{12}$ estudaram 100 transplantados hepáticos em Londres identificando $28 \%$ de lesões precursoras e uma incidência global de cancro cutâneo de $4 \%$ e $26 \%$ de infecções cutâneas (19\% de infecções fúngicas, $5 \%$ bacterianas e $2 \%$ virais). Lally et al ${ }^{9}$ avaliaram 308 transplantados renais em Oxford quanto à prevalência de patologia dermatológica benigna, tendo encontrado um elevado número de doenças infecciosas (verrugas virais $38 \%$, foliculite $27 \%$ e infecções fúngicas $18 \%$ ) mas também tumores cutâneos benignos (queratoses seborreicas 55\% ou polipos fibro-epiteliais $33 \%)$, hipertricose $(67 \%)$ e outros efeitos iatrogénicos (hiperplasia gengival $27 \%$ ou púrpura $41 \%)$.

No nosso estudo, salienta-se o predomínio de infecções cutâneas, principal motivo de consulta em $42,2 \%$ dos casos observados. Nas sub-populações estes diagnósticos apresentaram uma distribuição similar, quer nos doentes com transplante hepático $(40,4 \%)$ quer nos doentes com transplante renal $(44,4 \%)$. O risco de infecções em doentes submetidos a transplante de órgão sólido é determinado primariamente por dois factores: intensidade de exposição a potenciais agentes patogénicos e estado de imunossupressão. ${ }^{13}$ Para além de uma maior susceptibilidade a agentes patogénicos, estes indivíduos também estão sujeitos a uma maior e mais rápida progressão e concomitante maior gravidade das infecções comparativamente com a população imunocompetente. Daí a importância do diagnóstico e tratamento atempados das infecções. Dentro deste grupo, as infecções fúngicas foram as mais observadas $(20,5 \%)$, principalmente diagnósticos de dermatofitia, e em menor número infecções por Malassezia furfur e infecções por Candida spp. (Fig. 1a) Na pesquisa efectuada encontrámos um estudo realizado na Turquia por Güleç et $\mathrm{al}^{14} \mathrm{com}$ transplantados renais, em que foram identificadas infecções fúngicas superficiais em $63,7 \%$ dos 102 doentes estudados - 36,3\% com diagnóstico de pitiriase versicolor, 


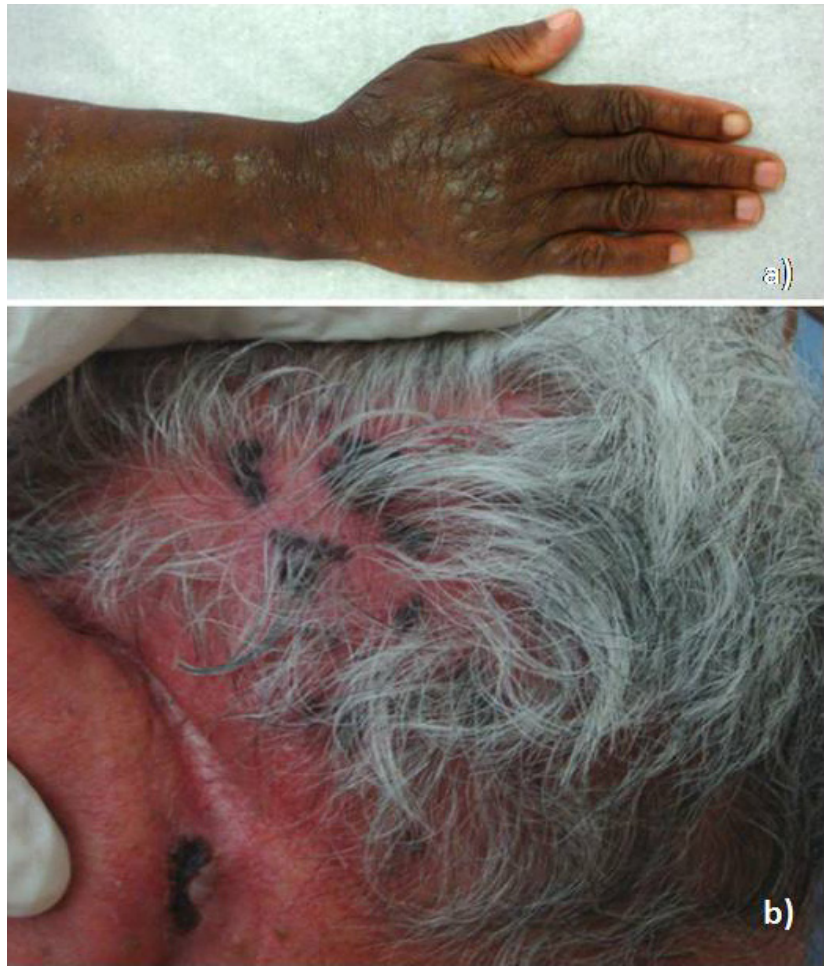

Figura 1 - a) Doente com dermatofitia por Trichophyton soudanense no membro superior; b) Doente com herpes zoster (dermátomo cervical C2).

candidíase oral-cutânea em $25,5 \%$, onicomicose em $12,7 \%$ e tinea pedis interdigital em $11,8 \%$, sendo o dermatófito mais frequentemente isolado $T$. rubrum, à semelhança do encontrado na nossa amostra. Na nossa população em $12,7 \%$ dos casos foram diagnosticadas infecções virais: manifestações da infecção pelo vírus do papiloma humano em $7,8 \%$, como verrugas vulgares ou condilomas ano-genitais, e infecções pelos vírus herpes em $4,9 \%$, dos quais três quartos dos casos corresponderam a infecções pelo vírus varicela-zoster (HHV3), nomeadamente herpes zoster. (Fig. 1b) Em 8,5\% dos casos foram identificadas infecções bacterianas, maioritariamente piodermites.

A modificação da resposta inflamatória que ocorre no doente transplantado tem de ser considerada. Salientamos a importância de uma correcta identificação da etiologia infecciosa, que por vezes pode apresentar-se de uma forma clínica e imagiológica menos evidente, o que pode condicionar atrasos no diagnóstico. Estas particularidades devem ser tidas em conta, não só pelas implicações na terapêutica anti-microbiana (por exemplo, exigindo períodos de tratamento mais prolongados, de largo espectro, etc.) mas também no estabelecimento de estratégias preventivas, através da instituição de terapêuticas profilácticas a longo prazo (como por exemplo anti-virais nas infecções recorrentes pelo vírus herpes simples, derivados imidazólicos nas infecções fúngicas, etc.) ou vacinação profiláctica nas infecções virais (como por exemplo vacinação contra $\mathrm{HPV}) .{ }^{10}$ São necessários mais estudos aleatorizados que comprovem o custo-benefício destas medidas.

Está descrito que os doentes sob imunossupressão

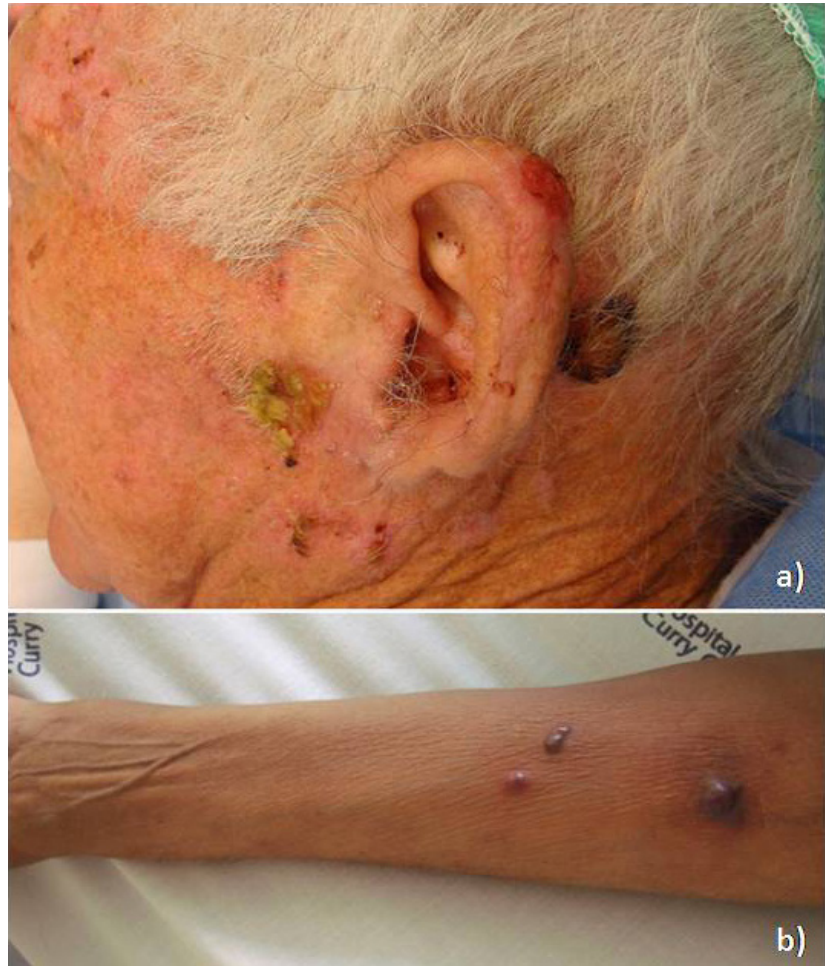

Figura 2 - a) Doente com queratoses actínicas e carcinomas espinocelulares; b) Doente com lesões de sarcoma de Kaposi no membro superior.

têm um risco elevado para desenvolver tumores cutâneos. ${ }^{5,10,15-16}$ Estima-se que após o transplante haja um risco 10 vezes superior de vir a ter um carcinoma basocelular, 65 vezes superior para o carcinoma espinocelular, 3 a 4 vezes superior para melanoma maligno, aproximadamente 20 vezes para o carcinoma de células de Merkel e 84 vezes superior para o sarcoma de Kaposi e que este risco é tanto maior quanto mais jovem for o indivíduo transplantado. .,17-19 Na nossa população o número de tumores cutâneos e lesões precursoras foi de $11,7 \%$. Estes diagnósticos assumiram maior importância na sub-população de doentes transplantados renais, tendo sido o motivo de consulta em $20,6 \%(37 / 180)$ dos casos, mas apenas em 4,8\% (11/230) nos doentes transplantados hepáticos. Estas diferenças podem estar relacionadas com o maior grau de imunossupressão a que os doentes transplantados renais estão sujeitos ou a períodos mais longos de imunossupressão em indivíduos com maior sobrevida. Mas não podemos retirar conclusões sobre este ponto pois estava fora do âmbito do nosso estudo caracterizar os diferentes esquemas de imunossupressão e a morbilidade e mortalidade associada a cada uma das sub-populações, também não comparadas em nenhum outro estudo na literatura. Na nossa amostra, foi estabelecido o diagnóstico de cancro cutâneo não melanoma (CCNM) em 33 de 48 casos $(68,8 \%)$ e lesões precursoras tais como queratoses actínicas ou queilite actínica em 12 casos. (Fig. 2a) O diagnóstico de melanoma maligno foi estabelecido num doente e foram apurados dois casos com sarcoma de Kaposi iatrogénico. (Fig. 2b) Em ambos os doentes com sarcoma de Kaposi, após tentativa 
de redução da terapêutica imunossupressora sem melhoria clínica, procedeu-se à substituição de ciclosporina por sirolimus com regressão completa das lesões ao fim de cerca de dois meses.

Apesar do número de doentes com queratoses actínicas não ser muito elevado na nossa amostra, esta patologia é bastante prevalente noutros estudos, como por exemplo $24 \%$ nos doentes transplantados renais estudados por Borges da Costa et $\mathrm{al}^{20}$ ou até $40 \%$ após cinco anos da data do transplante noutras séries. ${ }^{21} \mathrm{O}$ valor que encontrámos poderá ter sido influenciado pela idade média inferior a 62 anos ou pela maior proporção de transplantados hepáticos da nossa amostra. Relativamente aos casos de CCNM, na população em geral os carcinomas basocelulares (CBC) são o cancro cutâneo mais frequente. A título de exemplo, num estudo realizado em Portugal entre 1981 e 1993 por Amado et al $^{22}$ com base no Registo de Cancro do Hospital Geral de Santo António no Porto foi encontrada uma relação entre CBC e carcinoma espinocelular (CEC) de 2:1. Segundo dados gentilmente cedidos por Soares de Almeida do Laboratório de Histopatologia Cutânea do Hospital de Santa Maria em Lisboa, entre 2006 e 2009 a relação entre CBC:CEC foi de 4,2-5,5:1. Contrariamente, alguns estudos realizados em Portugal com doentes transplantados renais mostraram um predomínio de CEC sobre os casos de CBC, 1,33:1 nos doentes estudados por Marques et al $^{16}$ nos Hospitais da Universidade de Coimbra e 1,38:1 nos doentes estudados por Cunha et al $^{15}$ no Hospital Curry Cabral em Lisboa. No nosso estudo, a sub-população de transplantados renais apresentou um concordante predomínio de CEC (razão CEC:CBC de 1,3:1), mas a sub-população de transplantados hepáticos apresentou um predomínio de CBC (razão CBC:CEC de 3,5:1). Contudo, noutros estudos com doentes transplantados renais, o número de CEC diagnosticados não ultrapassou o de CBC, como por exemplo na população estudada por Borges da Costa et at ${ }^{20}$ (razão CBC:CEC de 1:1) ou noutras populações Mediterrânicas, como por exemplo o estudo realizado em Espanha por Fuente et $\mathrm{al}^{23}$ (razão CBC:CEC de 1,4:1) ou o estudo realizado por Naldi et $\mathrm{al}^{24} \mathrm{com}$ doentes Italianos (razão CBC:CEC de 2,1:1).

Dado o significativo número de CCNM nas populações de doentes transplantados, não deve ser desprezada a importante morbilidade associada a estes diagnósticos bem como o elevado consumo de recursos que a sua abordagem implica. Os tumores cutâneos não-melanoma frequentemente contêm mutações em genes supressores tumorais, como o p53, relacionadas com a exposição à radiação ultravioleta (UV), principal factor de risco associado ao desenvolvimento destas neoplasias na população em geral. Para além das lesões fotoinduzidas prévia e posteriormente ao transplante, outros factores também podem contribuir para a patogénese do cancro cutâneo não-melanoma nestes doentes, tais como a redução da imunovigilância, factores imunogenéticos (haplotipo HLA, mismatching dador-receptor), efeitos particulares dos fármacos imunossupressores (azatioprina com efeito carcinogénico directo, indução da produção de TGFbeta pela ciclosporina) e o possível papel da infecção pelo HPV. ${ }^{17,25-28}$ Dada a prevalência deste tipo de patologia, não deve ser descurado o estabelecimento de estratégias de prevenção e tratamento do cancro cutâneo nesta população de alto risco. Para além de medidas a instituir precocemente, tais como a utilização diária de filtros solares, vestuário adequado e adopção de hábitos de exposição solar correctos, também podem ser equacionadas estratégias complementares, tais como a diminuição ou modificação da terapêutica imunossupressora, iniciar terapêutica profiláctica com acitretina ou capecitabina (após rastreio do défice da dihidropirimidina desidrogenase) ou utilização a título preventivo de inibidores mTOR (por exemplo sirolimus) pelo seu efeito anti-tumoral/anti-proliferativo. ${ }^{29-33}$

As manifestações cutâneas potencialmente relacionadas com efeitos secundários dos fármacos também foram muito frequentes. Estes efeitos secundários podem interferir com a adesão à terapêutica, daí que a sua identificação e abordagem adequadas sejam importantes e cruciais para a sobrevida do enxerto. Existem muitas vias para a imunossupressão, cujas escolhas terapêuticas têm vindo a variar ao longo dos últimos anos. Por exemplo, de 2000 em diante ocorreu uma redução progressiva da utilização da azatioprina passando a ser mais utilizado o micofenolato de mofetil, ou substituição da ciclosporina pelo tacrolimus. ${ }^{10}$ Na nossa amostra, em 10,5\% das consultas identificámos manifestações cutâneas relacionadas com efeitos secundários de fármacos. Os diagnósticos mais observados foram a erupção acneiforme $(3,4 \%)$ e as toxidermias $(3,2 \%)$, em que os exantemas morbiliformes ou maculopapulares medicamentosos retardados foram os mais observados. O longo tempo médio observado entre o transplante e o início das manifestações cutâneas pode representar, por exemplo, alterações de fármacos imunossupressores, mas também a introdução concomitante de outras terapêuticas, tal como antibioterapia, entre outras. Todos os doentes com diagnóstico de erupção acneiforme observados estavam sob terapêutica com corticosteróide dos quais quatro também estavam medicados com sirolimus, podendo o diagnóstico ser imputado a qualquer um dos fármacos. Os dois doentes observados por estrias $(0,5 \%)$ e os seis casos de púrpura $(1,5 \%)$ também estavam sob terapêutica com corticosteróide, e podem ser enquadradas nas manifestações cutâneas cushingóides habitualmente em relação com o referido fármaco. Os casos de hirsutismo/hipertricose $(1,5 \%)$ ocorreram em doentes sob terapêutica com ciclosporina, tal como a hiperplasia gengival, que apenas foi observada num caso. Também apenas foi observado um caso de úlceras orais, em relação com a terapêutica com sirolimus. Relativamente ao último diagnóstico referido, a prevalência deste efeito secundário nos doentes medicados com sirolimus pode atingir até $24 \%$ na literatura ${ }^{34}$ no entanto não foi identificado em nenhum dos doentes transplantados renais referenciados à nossa Consulta de Dermatologia, dos quais $20,2 \%$ estava sob terapêutica com inibidores mTOR. Não consideramos que a sub-referenciação traduza menos 
eventos ocorridos mas sim doentes que não necessitaram de ser referenciados porque foram tratados de forma eficaz pelas equipas das Unidades de Transplantação.

Não é de desprezar o elevado número de consultas por outras patologias dermatológicas não iatrogénicas (35,6\%). Apesar de não estarem directamente relacionadas com a imunossupressão, devemos ter presente a possível interferência destes fármacos em dermatoses crónicas pré-existentes. No global, identificámos $9,5 \%$ casos com eczema, $8,3 \%$ com nevos melanocíticos ou tumores cutâneos benignos, $6,6 \%$ com dermite seborreica e prurido/xerose cutânea em $3,2 \%$, sendo que os restantes doentes tinham outras dermatoses. Salienta-se, neste último grupo, um doente com exacerbação de uma dermatose inflamatória pré-existente. Tratava-se de um doente com agravamento de psoríase vulgar em placas após interrupção da ciclosporina durante um ajuste da terapêutica imunossupressora. Relativamente às sub-populações, estes diagnósticos foram maioritariamente observados nos doentes com transplante hepático $(42,6 \%$ vs $26,7 \%$ dos doentes com transplante renal) e que também foi a sub-população mais referenciada à Consulta de Dermatologia e Venereologia.

Apesar do grande número de doentes incluídos no presente estudo, ele tem algumas limitações. Por um lado trata-se de um estudo retrospectivo, limitando o controlo de algumas variáveis cujos dados não estavam disponíveis. Por outro lado, os dados foram obtidos através da revisão dos diários clínicos e o estudo foi baseado no diagnóstico clínico, sendo importante ressalvar a existência de algumas lacunas nos registos e na solicitação de exames histológico, bacteriológico ou micológico, a qual não foi realizada de forma consistente. Outro dos aspectos a salientar é o facto de, na nossa amostra, não ter sido contabilizada a patologia aguda, que é na maior parte dos casos observa- da directamente na Enfermaria da Unidade de Transplantação e não em regime de consulta. Não podemos deixar de referir a importante interferência dos diferentes esquemas possíveis de terapêutica imunossupressora nas diferenças encontradas, e que não foi tida em conta neste estudo, a avaliar em estudos posteriores.

\section{CONCLUSÃO}

O aperfeiçoamento das técnicas cirúrgicas e dos cuidados prestados pelas Equipas médicas especializadas em Transplantação e os novos tratamentos imunossupressores contribuem para um aumento da sobrevida dos doentes transplantados. Dada a elevada frequência de patologia do foro dermatológico encontrada na nossa revisão retrospectiva destes doentes e pela importante morbilidade e repercussões sociais e económicas que comporta, é essencial incluir o acesso a consultas de Dermatologia e Venereologia nos cuidados multi-disciplinares prestados pós-transplante, permitindo uma abordagem adequada das manifestações cutâneas que possam vir a desenvolver. Não só através de identificação e orientação correcta das infecções cutâneas, mas também pelo auxílio no controlo dos efeitos secundários relacionados com a terapêutica imunossupressora e pela possibilidade de desenvolver uma intervenção activa na prevenção e detecção precoce de patologia neoplásica.

\section{CONFLITOS DE INTERESSE}

Os autores declaram não existir qualquer conflito de interesses relativamente a este artigo.

\section{FONTES DE FINANCIAMENTO}

Não existiram fontes externas de financiamento para a realização deste artigo

\section{REFERÊNCIAS}

1. Koranda FC, Dehmel EM, Kahn G, Penn I. Cutaneous complications in immunosuppressed renal homograft recipients. JAMA. 1974;229:419924.

2. Cohen E, Komorowski RA, Clowry LJ. Cutaneous complications in renal transplant recipients. Am J Clin Pathol. 1987;88:32-7.

3. McLelland J, Rees A, Williams G, Chu T. The incidence of immunosuppression related skin disease in long-term transplant patients. Transplantation. 1988;46:871-4.

4. Barba A, Tessari G, Boschiero L, Chieregato GC. Renal transplantation and skin diseases: review of the literature and results of a 5-year followup of 285 patients. Nephron. 1996;73:131-6.

5. Euvrard S, Kanitakis J, Claudy A. Skin cancers after organ transplantation. N Engl J Med. 2003;348:1681-91.

6. Menni S, Beretta D, Piccino R, Ghio L. Cutaneous and oral lesions in 32 children after renal transplantation. Pediatr Dermatol. 1991;8:194-8.

7. Halpert E, Tunnessen WW Jr, Fivush B, Case B. Cutaneous lesions associated with cyclosporine therapy in pediatric renal transplant recipients. J Pediatr. 1991;119:489-91.

8. Euvrard S, Kanitakis J, Cochat P, Cambazard F, Claudy A. Skin diseases in children with organ transplants. J Am Acad Dermatol. 2001;44:932-9.

9. Lally A, Casabonne D, Imko-Walczuk B, Newton R, Wojnarowska F. Prevalence of benign cutaneous disease among Oxford renal transplant recipients. J Eur Acad Dermatol Venereol. 2011;25:462-70.

10. Otley CC, Stasko T, Griffin MD, Murphy GM, Hirose R, Chong AH, editors. Skin disease in organ transplantation. New York: Cambridge University Press; 2008

11. Wisgerhof HC, Edelbroek JR, de Fijter JW, Feltkamp MC, Willemze R,

Bouwes Bavinck JN. Trends of skin diseases in organ-transplant recipients transplanted between 1966 and 2006: a cohort study with follow-up between 1994 and 2006. Br J Dermatol. 2010;162:390-6.

12. Perera GK, Child FJ, Heaton N, O'Grady J, Higgins EM. Skin lesions in adult liver transplant recipients: a study of 100 consecutive patients. $\mathrm{Br}$ J Dermatol. 2006;154:868-72.

13. Fishman JA. Infection in solid-organ transplant recipients. N Engl J Med. 2007;357:2601-14.

14. Güleç AT, Demirbilek M, Seçkin D, Can F, Saray Y, Sarifakioglu E, et al. Superficial fungal infections in 102 renal transplant recipients: a casecontrol study. J Am Acad Dermatol. 2003;49:187-92.

15. Cunha D, Carvalho R, Chaveiro A, Papoila A, Assis Pacheco A, Lamarão $P$, et al. Tumores cutâneos em doentes transplantados renais seguidos nas consultas de dermatologia e transplante renal do Hospital Curry Cabral, XXIII Congresso Português de Nefrologia; 2009 Março; Algarve, Portugal.

16. Marques C, Serejo M, Domingues JC, Freitas JD, Poiares Baptista A Tumores malignos cutâneos em transplantados renais. Trab Soc Port Dermatol Venereol. 1995;53:207-17.

17. Harwood CA, Proby CM, McGregor JM, Sheaff MT, Leigh IM, Cerio R. Clinicopathologic features of skin cancer in organ transplant recipients: A retrospective case-control series. J Am Acad Dermatol. 2006;54:290300 .

18. Adami J, Gäbel H, Lindelöf B, Ekström K, Ryhd B, Glimelius B, et al. Cancer risk following organ transplantation: a nation-wide cohort study in Sweden. Br J Cancer. 2003;89:1221-7.

19. Moloney FJ, Comber H, O'Lorcain P, O'Kelly P, Conlon PJ, Murphy GM. 
A population-based study of skin cancer incidence and prevalence in renal transplant recipients. Br J Dermatol. 2006;154:498-504.

20. Borges-Costa J, Vasconcelos JP, Travassos AR, Guerra J, Santana A, Weigert A, et al. Cancro cutâneo em doentes com transplante renal: Incidência e associações com fatores clínicos e sociodemográficos. Acta Med Port. 2013;26:123-6.

21. Euvrard S, Kanitakis J, Pouteil-Noble C, Dureau G, Touraine JL, Faure $\mathrm{M}$, et al. Comparative epidemiologic study of premalignant and malignant epithelial cutaneous lesions developing after kidney and heart transplantation. J Am Acad Dermatol. 1995;33:222-9.

22. Amado J, Oliveira M, Cunha Velho G, Costa V, Torres FO, Massa A. Cancro da pele. Acta Med Port. 1998;11:529-32.

23. Fuente MJ, Sabat M, Roca J, Lauzurica R, Fernández-Figueras MT, Ferrándiz C. A prospective study of the incidence of skin cancer and its risk factors in a Spanish Mediterranean population of kidney transplant recipients. Br J Dermatol. 2003;149:1221-6.

24. Naldi L, Fortina AB, Lovati S, Barba A, Gotti E, Tessari G, et al. Risk of nonmelanoma skin cancer in Italian organ transplant recipients. A registry-based study. Transplantation. 2000;70:1479-84.

25. Hojo M, Morimoto T, Maluccio M, Asano T, Morimoto K, Lagman M, et al. Cyclosporine induces cancer progression by a cell-autonomous mechanism. Nature. 1999;397:530-4.

26. Brash DE, Rudolph JA, Simon JA, Lin A, McKenna GJ, Baden HP, et al. A role for sunlight in skin cancer: UV induced p53 mutations in squamous cell carcinoma. Proc Natl Acad Sci U S A. 1991;88:10124-8.

27. McGregor JM, Berkhout RJ, Rozycka M, ter Schegget J, Bouwes Bavincke JN, Brooks L, et al. P53 mutations implicate sunlight in post- transplant skin cancer irrespective of human papillomavirus status. Oncogene. 1997; 15:1737-40.

28. Berg D, Otley CC. Skin cancer in organ transplant recipients: Epidemiology, pathogenesis and management. J Am Acad Dermatol. 2002;47:117.

29. Harwood CA, Leedham-Green M, Leigh IM, Proby CM. Low-dose retinoids in the prevention of cutaneous squamous cell carcinomas in organ transplant recipients: a 16-year retrospective study. Arch Dermatol. 2005; 141:456-64.

30. George R, Weightman W, Russ GR, Bannister KM, Mathew TH. Acitretin for chemoprevention of non-melanoma skin cancers in renal transplant recipients. Australas J Dermatol. 2002;43:269-73.

31. Jirakulaporn T, Endrizzi B, Lindgren B, Mathew J, Lee PK, Dudek AZ. Capecitabine for skin cancer prevention in solid organ transplant recipients. Clin Transplant. 2011;25:541-8.

32. Euvrard S, Morelon E, Rostaing L, Goffin E, Brocard A, Tromme I, et al. Sirolimus and Secondary Skin-Cancer Prevention in Kidney Transplantation. N Engl J Med. 2012;367:329-39.

33. Borges da Costa J, Travassos AR, Vasconcelos J, Guerra J, Santana A, Weigert A, et al. Conhecimento sobre cancro de pele e hábitos de fotoproteção em transplantados: Estudo descritivo de 127 doentes com transplante renal. Rev Soc Por Dermatol Venereol. 2012;70:313-7.

34. Montalbano M, Neff GW, Yamashiki N, Meyer D, Bettiol M, SlapakGreen $G$, et al. A retrospective review of liver transplant patients treated with sirolimus from a single center: an analysis of sirolimus-related complications. Transplantation. 2004;78:264-8. 